Hydrol. Earth Syst. Sci., 17, 2195-2208, 2013

www.hydrol-earth-syst-sci.net/17/2195/2013/

doi:10.5194/hess-17-2195-2013

(C) Author(s) 2013. CC Attribution 3.0 License.

\title{
Radar subpixel-scale rainfall variability and uncertainty: lessons learned from observations of a dense rain-gauge network
}

\author{
N. Peleg ${ }^{1}$, M. Ben-Asher ${ }^{2}$, and E. Morin ${ }^{3}$ \\ ${ }^{1}$ Institute of Earth Sciences, Hebrew University of Jerusalem, Jerusalem, Israel \\ ${ }^{2}$ Department of Geological \& Environmental Sciences, Ben Gurion University of the Negev, Beer-Sheva, Israel \\ ${ }^{3}$ Department of Geography, Hebrew University of Jerusalem, Jerusalem, Israel
}

Correspondence to: N. Peleg (nadav.peleg@mail.huji.ac.il)

Received: 11 December 2012 - Published in Hydrol. Earth Syst. Sci. Discuss.: 2 January 2013

Revised: 4 May 2013 - Accepted: 9 May 2013 - Published: 14 June 2013

\begin{abstract}
Runoff and flash flood generation are very sensitive to rainfall's spatial and temporal variability. The increasing use of radar and satellite data in hydrological applications, due to the sparse distribution of rain gauges over most catchments worldwide, requires furthering our knowledge of the uncertainties of these data. In 2011, a new superdense network of rain gauges containing 14 stations, each with two side-by-side gauges, was installed within a $4 \mathrm{~km}^{2}$ study area near Kibbutz Galed in northern Israel. This network was established for a detailed exploration of the uncertainties and errors regarding rainfall variability within a common pixel size of data obtained from remote sensing systems for timescales of $1 \mathrm{~min}$ to daily. In this paper, we present the analysis of the first year's record collected from this network and from the Shacham weather radar, located $63 \mathrm{~km}$ from the study area. The gauge-rainfall spatial correlation and uncertainty were examined along with the estimated radar error. The nugget parameter of the inter-gauge rainfall correlations was high ( 0.92 on the $1 \mathrm{~min}$ scale) and increased as the timescale increased. The variance reduction factor (VRF), representing the uncertainty from averaging a number of rain stations per pixel, ranged from $1.6 \%$ for the $1 \mathrm{~min}$ timescale to $0.07 \%$ for the daily scale. It was also found that at least three rain stations are needed to adequately represent the rainfall $(\mathrm{VRF}<5 \%)$ on a typical radar pixel scale. The difference between radar and rain gauge rainfall was mainly attributed to radar estimation errors, while the gauge sampling error contributed up to $20 \%$ to the total difference. The ratio of radar rainfall to gauge-areal-averaged rainfall, expressed by the error distribution scatter parameter, decreased from $5.27 \mathrm{~dB}$ for 3 min timescale to $3.21 \mathrm{~dB}$ for the
\end{abstract}

daily scale. The analysis of the radar errors and uncertainties suggest that a temporal scale of at least $10 \mathrm{~min}$ should be used for hydrological applications of the radar data. Rainfall measurements collected with this dense rain gauge network will be used for further examination of small-scale rainfall's spatial and temporal variability in the coming years.

\section{Introduction}

Complex interactions exist between the spatial and temporal variability of rainfall and watershed hydrological responses (Morin et al., 2006). This has been demonstrated by several hydrological studies: Singh (1997) discussed how the spatial and temporal variability of rainfall affects the runoff hydrograph and peak discharge; Arnaud et al. (2011) indicated that large catchments, on the scale of hundreds of square kilometers, are more sensitive than small catchments to uncertainties resulting from not considering the spatial variability of the rainfall; Zoccatelli et al. (2011) pointed out that the catchment response is sensitive to the rainfall's spatial variability, even for small catchment sizes (a few dozen square kilometers), and that neglecting the spatial variability would affect runoff timing; Rozalis et al. (2010) established a hydrological model for flash-flood prediction and found it to be very sensitive to the temporal variability of the rainfall, affecting both runoff amount and peak discharge; Faures et al. (1995) indicated that knowing the spatial variability of convective rainfall is essential, even for catchments of very small scale (less than a few square kilometers) when conducting hydrological modeling; Bahat et al. (2009) found that rainfall 
uncertainty dominates uncertainties in runoff prediction for a catchment smaller than $1 \mathrm{~km}^{2}$; Berne et al. (2004) found that hydrological applications for urban catchments of the order of few square $\mathrm{km}$ require a high resolution of temporal (3$5 \mathrm{~min})$ and spatial $(2-3 \mathrm{~km})$ rainfall data.

Rainfall is usually measured for hydrological applications by rain-gauge networks, weather radars or satellites. Although rain gauges are the most commonly used source, they are often too sparsely distributed; only a few dense raingauge networks worldwide adequately cover entire catchments. Weather radar records rainfall at high spatial and temporal resolution (e.g. $1.5 \mathrm{~km}^{2}$ and $3 \mathrm{~min}$ - see Sect. 2), which is suitable for most hydrological modeling purposes. Satellite-based rainfall estimates can also be used for hydrological applications but they typically represent larger space and timescales and can potentially be applied to large catchments (as discussed by Nikolopoulos et al., 2010). The increasing use of radar and satellite data in hydrological applications requires improving our knowledge of the uncertainties of these data (see a recent discussion by Berne and Krajewski (2013) of current limitations and challenges in the use of weather radars in hydrology). A main difficulty in this regard is that remotely sensed rainfall estimates are provided in spatially averaged pixels (typically $1-4 \mathrm{~km}^{2}$ ) and no equivalent ground reference data are available because of the abovementioned sparseness of rain-gauge networks (see extensive discussion by Krajewski and Smith, 2002). In 2003, Krajewski et al. (2003) declared that "new designs of the rain gauge networks should be considered" to learn more about the highresolution variability of rainfall. Almost a decade later, Krajewski et al. (2010) summarized their paper by stating that "one key factor in solving the persistent problem of radarrainfall uncertainties is the availability of dense rain gauge networks that could provide valuable information for modeling these uncertainties". In 2011, a new super-dense network of rain gauges was installed in northern Israel. This network was established to explore in detail the uncertainties and errors caused by rainfall variability at remote-sensing subpixel resolution. This is the first step in continuing research to expand our knowledge of the spatial and temporal variability of rainfall at scales below $2 \mathrm{~km}$.

Several studies have dealt with rainfall variability at pixel and subpixel scales: in 1998, Krajewski et al. (1998) recognized the need to establish rain-gauge networks at the radar subpixel scale to estimate radar-rainfall uncertainty. They deployed a network, which included 10 stations (see configuration in Krajewski et al., 2003), in the Iowa City Municipal Airport. Habib et al. (2001b) used this network to estimate the errors resulting from the use of tipping-bucket rain gauges with the aim of capturing the rainfall's small-scale temporal variability. By fitting a nonparametric regression on rainfall data collected from 15 collocated rain gauges (EVAC PicoNet network, Oklahoma), Ciach (2003) analyzed the local random errors of tipping-bucket rain gauges on a smaller scale. Later, Ciach and Krajewski (2006) used the PicoNet to analyze the spatial correlation of the rainfall over a $3 \times 3 \mathrm{~km}$ area; Ciach and Krajewski (1999) introduced the error separation method which distinguishes the rain-gauge sampling error from the radar rainfall estimation error. They used a network of five rain gauges with a scale similar to that of the radar pixel. Data from the PicoNet were also used by Seo and Krajewski (2011) to test the assumption that the covariance between radar rainfall error and rain gauge error in representing the radar sampling domain is negligible when using the error separation method. Two dense networks of eight gauges within a $4 \mathrm{~km}^{2}$ grid located at the Brue catchment were used by Wood et al. (2000) to estimate the errors of the individual gauge and radar compared to the "true" mean areal rainfall. This network was later used by Villarini et al. (2008) to assess the errors resulting from temporal gaps in rainfall observations and the uncertainties resulting from areal-topoint estimations. Habib et al. (2001a) estimated the correlation coefficient of point rainfall using a clustered network of rain gauges deployed in Florida (TEFLUN-B network). Gebremichael and Krajewski (2004) used both TEFLUN$\mathrm{B}$ and TRMM-LBA networks to estimate the radar's ability to characterize the small-scale spatial variability of rainfall by comparing the correlation function of the gauge and the radar. A network consisting of nine optical rain gauges within $500 \times 500 \mathrm{~m}$ was deployed in Denmark by Jensen and Pedersen (2005) to explore the radar subpixel-scale rainfall variation. Pedersen et al. (2010) used the same network to determine the coefficient of variation and the spatial correlation of the rainfall field. Fiener et al. (2009) installed a network consisting of 13 tipping-bucket rain gauges on a $1.4 \mathrm{~km}^{2}$ area in Germany to determine the spatial variability of rainfall on a subkilometer scale, taking into account the wind's potential effect. The Walnut Gulch Experimental Watershed (WGEW), equipped with about 10 rain gauges per every TRMM Precipitation Radar pixel ( $\sim 5 \mathrm{~km}$ in diameter), was used by Amitai et al. (2012) who conducted rain rate comparisons of these two resources for a semiarid climate. Several studies have explored the small-scale spatial variability of the rainfall drop size distribution (DSD) (Tapiador et al., 2010; Tokay et al., 2010). Jaffrain et al. (2011) deployed 16 optical disdrometers over a $1 \times 1 \mathrm{~km}$ area in Switzerland and determined the coefficient of variation of the total concentration of drops, the mass-weighted diameter and the rain rate over the network.

In the current study we set up the first step toward estimating the subpixel sampling uncertainties and the errors of weather radar rainfall estimates using a super dense raingauge network. This network is located in a different climatological area than the above presented networks. In this paper we wish to first present our network (current results and future plans) to the hydrological community as part of the global effort to enhance the knowledge of small-scale rainfall variability and radar uncertainty; and secondly, to present three lessons learned from the first year of observations regarding (1) the spatial correlation of convective 


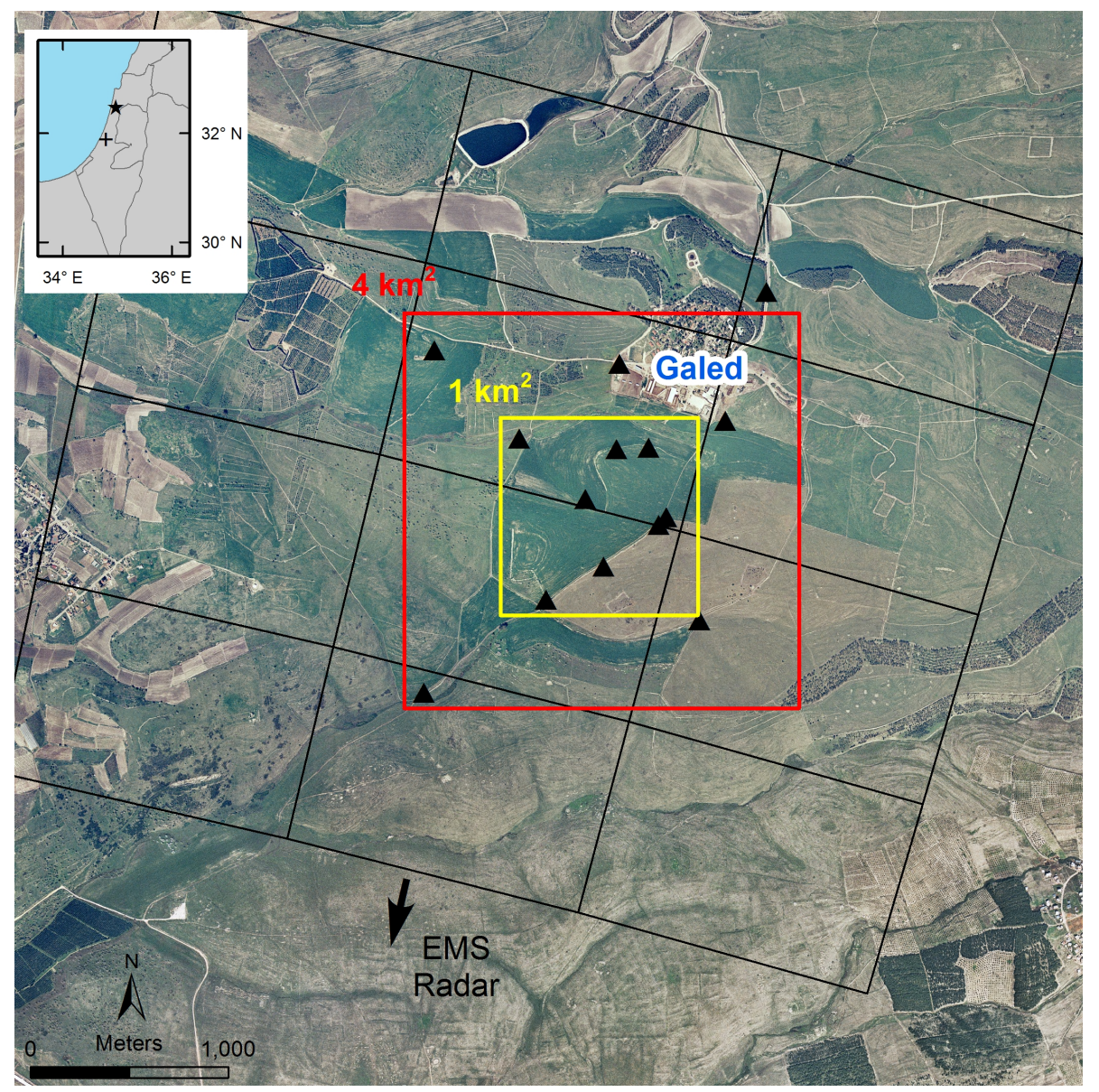

Fig. 1. Map of the study area including the 14 rain stations (triangles) around Kibbutz Galed. Each station is composed of two rain gauges. The black grid represents the radar mesh, with a spatial polar resolution of $1.4^{\circ} \times 1 \mathrm{~km}$. Inset shows the general location of the network in Israel (star) and the location of the EMS weather radar (cross).

and nonconvective rainfall; (2) the number of rain gauges required to adequately measure rainfall in a radar subpixel scale; and (3) the decision as to which radar temporal resolution should be used for hydrological modeling due to the radar errors at the pixel scale. The paper is composed of six sections: Sect. 2 is dedicated to technical information regarding the rain gauge network's installation and data quality control (QC). This section also contains information about the weather radar and rainfall estimations. The rainfall spatial correlation is described in Sect. 3. The uncertainty quantification for the mean areal rainfall representing the subpixel level is discussed in Sect. 4. The radar rainfall error variance and the radar evaluation are presented in Sect. 5. The conclusions, discussion on the lessons learned, and near-future plans for the rain-gauge network are presented in Sect. 6 .

\section{Data}

\subsection{Galed dense rain-gauge network}

A very dense network of rain gauges was deployed in November 2011 near Kibbutz Galed, about $15 \mathrm{~km}$ east of northern Israel's coastline (Fig. 1). The network consists of 27 rain gauges, maintained by the Hydrometeorology Lab of the Hebrew University of Jerusalem, and one additional rain gauge operated by the Israel Meteorology Service. The rain gauges are deployed in 14 stations each with two sideby-side gauges (as in the Iowa network, Krajewski et al., 2003) covering an area of about $4 \mathrm{~km}^{2}$ in the fields surrounding the Kibbutz (Fig. 1). This network differs spatially, but is in a similar range as the networks used in previous studies, for example: the EVAC PicoNet in Oklahoma City with 25 rain stations deployed over $9 \mathrm{~km}^{2}$ (Ciach and Krajewski, 2006), the Scheyern Experimental Farm with 10 rain gauges over $1.4 \mathrm{~km}^{2}$ (Fiener et al., 2009), the Aarhus network consisting of 9 gauges equally spaced within a $0.25 \mathrm{~km}^{2}$ area (Jensen and Pedersen, 2005; Pedersen et al., 2010) or the 
Table 1. Intra-distances (m) of the rain stations.

\begin{tabular}{|c|c|c|c|c|c|c|c|c|c|c|c|c|c|c|}
\hline & 1 & & & & & & & & & & & & & \\
\hline 1 & 0 & 2 & & & & & & & & & & & & \\
\hline 2 & 1709 & 0 & 3 & & & & & & & & & & & \\
\hline 3 & 2672 & 1735 & 0 & 4 & & & & & & & & & & \\
\hline 4 & 1457 & 620 & 1375 & 0 & 5 & & & & & & & & & \\
\hline 5 & 1395 & 1076 & 1277 & 456 & 0 & 6 & & & & & & & & \\
\hline 6 & 1102 & 1052 & 1572 & 497 & 298 & 0 & 7 & & & & & & & \\
\hline 7 & 990 & 1193 & 1684 & 658 & 413 & 162 & 0 & 8 & & & & & & \\
\hline 8 & 1699 & 1918 & 1444 & 1298 & 842 & 962 & 912 & 0 & 9 & & & & & \\
\hline 9 & 1920 & 1386 & 777 & 829 & 548 & 843 & 930 & 785 & 0 & 10 & & & & \\
\hline 10 & 1620 & 1392 & 1111 & 778 & 354 & 598 & 645 & 557 & 336 & 0 & 11 & & & \\
\hline 11 & 1250 & 1448 & 1516 & 846 & 419 & 426 & 363 & 549 & 740 & 406 & 0 & 12 & & \\
\hline 12 & 1303 & 1440 & 1461 & 831 & 392 & 438 & 395 & 525 & 685 & 350 & 57 & 0 & 13 & \\
\hline 13 & 686 & 1518 & 2057 & 1049 & 812 & 570 & 412 & 1019 & 1284 & 963 & 572 & 628 & 0 & 14 \\
\hline 14 & 830 & 940 & 1938 & 634 & 708 & 434 & 450 & 1362 & 1253 & 1032 & 813 & 841 & 610 & 0 \\
\hline
\end{tabular}

8 gauges deployed in a $4 \mathrm{~km}^{2}$ area of the Brue catchment (Moore et al., 2000).

The stations are distributed in a nonuniform design (Fig. 1), according to the terrain's limitations (e.g. field crops, small streams, woods). The intra-distances of the rain stations (see Table 1) vary between 57 and 2,672 $\mathrm{m}$. Each station consists of two high-precision tipping-bucket rain gauges separated by about $1 \mathrm{~m}$ (as suggested by Ciach and Krajewski, 1999; Krajewski et al., 2003) to maintain better quality control and to acquire data on the zero-distance correlation of the rainfall. The tipping-bucket rain gauge was manufactured by YOUNG Company (model 52203). It has an orifice diameter of $18 \mathrm{~cm}$ with rainfall measurement resolution of $0.1 \mathrm{~mm}$ per tip and accuracy of $3 \%$ up to $50 \mathrm{~mm} \mathrm{~h}^{-1}$. Each rain gauge is connected to a HOBO data logger (model UA003-64). The maximum sampling frequency of the data logger is $1 \mathrm{~Hz}$, with a memory of $64 \mathrm{~K}$ bytes (more than enough for $1 \mathrm{yr}$ of measurements). This stands with the recommendations by Habib et al. (2001b) and Wang et al. (2008) to use a gauge bucket size of up to $0.254 \mathrm{~mm}$ with a temporal resolution of $1 \mathrm{~s}$. The HOBO logger's time accuracy is about 1 min per month. The loggers were synchronized each time the data were downloaded (approximately every three weeks) to minimize the potential problem of the loggers clocks' drift. In addition, we used 1 min time intervals accumulated from the $1 \mathrm{~s}$ temporal resolution to reduce errors.

The study area has a Mediterranean climate; its rainy season lasts from October to May (mean annual rainfall is $550 \mathrm{~mm}$ ), while June to September are typically dry and hot. In this study, we present the analysis of the first year record collected from 1 November 2011 to 1 May 2012. The accumulated rainfall for this period, indicated by counting the number of tips in $1 \mathrm{~min}$ time intervals, is equal to $512 \mathrm{~mm}$ (averaged over the rain gauges) and is divided into 63 rain events. A rain event is defined as beginning when the first rain tip is detected in one of the rain gauges and ending when there is an intermission of more than $15 \mathrm{~min}$ in rainfall for all gauges. Rain events with cumulative rainfall depth of less than $0.5 \mathrm{~mm}$ for all gauges were excluded. An inherent problem with tipping-bucket-derived rain intensities is that only the time at which the bucket is completely filled is recorded and no information is available on the actual period of time it took to get filled. To overcome this problem, a backward linear interpolation to the previous recorded tip was applied, with two exceptions: (1) the time interval from the previous tip was larger than $15 \mathrm{~min}$, or (2) this was the first tip in the rain event. Note that low rain intensities are more vulnerable to the above-mentioned problem.

To ensure reliability of the results, QC procedures were conducted. This is essential, as the data collected from the rain gauges may be corrupted due to partial clogging of the funnel by debris or small living creatures (for example, wasps or snails), or technical problems (such as a low battery) resulting in lack of measurements at a given time. Most of the errors were detected by comparing the rain intensity of rain gauge couples at each station and the rain event. In addition, the rain intensities of all of the gauges were compared for each rain event. All data which were considered to be corrupted were removed during the QC, ensuring a lack of intraand inter-station measurement errors. After QC, rain intensity time series for time intervals between $1 \mathrm{~min}$ and daily timescales were computed for each rain gauge.

\subsection{Radar data}

Data from the Shacham (EMS) Mekorot company weather radar system located at Ben Gurion Airport, about $63 \mathrm{~km}$ south of the study area, were used in this study. Data from this radar have been used extensively for climatology and hydrology studies over the last decade (see Karklinsky and Morin, 2006; Morin et al., 2001, 2009; Morin and Gabella, 2007; Peleg and Morin, 2012; Rozalis et al., 2010; Yakir and Morin, 2011). The radar is a C-band (5.35 cm wavelength), non-Doppler system with a maximal transmitting power of 
Table 2. Radar pixels after $Z-R$ bias adjustment. Sum $\left(R_{\mathrm{r}}\right)$ represents the accumulated rainfall for the studied period and $\operatorname{Sum}\left(R_{\mathrm{r}}\right.$ $R_{\mathrm{t}}^{-1}$ ) is the ratio between radar rainfall and rain gauge rainfall (averaged over the gauges) for the studied period.

\begin{tabular}{ccc}
\hline Radar ID & $\operatorname{Sum}\left(R_{\mathrm{r}}\right)(\mathrm{mm})$ & $\operatorname{Sum}\left(R_{\mathrm{r}} R_{\mathrm{t}}^{-1}\right)$ \\
\hline 10054 & 444.3 & $97.9 \%$ \\
10055 & 413.6 & $91.2 \%$ \\
10056 & 431.9 & $95.2 \%$ \\
10057 & 429.8 & $94.7 \%$ \\
11054 & 466.8 & $102.9 \%$ \\
11055 & 442.5 & $97.5 \%$ \\
11056 & 449.4 & $99 \%$ \\
11057 & 447.3 & $98.6 \%$ \\
12054 & 477.2 & $105.2 \%$ \\
12055 & 430 & $94.8 \%$ \\
12056 & 443.9 & $97.8 \%$ \\
12057 & 455.7 & $100.4 \%$ \\
\hline
\end{tabular}

$250 \mathrm{~kW}$, a temporal resolution of about $3 \mathrm{~min}$ per volume scan, and a spatial polar resolution of $1.4^{\circ} \times 1 \mathrm{~km}$ in space (see grid in Fig. 1). Data from an elevation angle of $1^{\circ}$ (mean elevation of $1255 \mathrm{~m}$ above the network) were used for the analysis. No pixels with substantial ground clutter or beam blockage were detected in the analyzed region.

A total of 11827 radar volume scans were analyzed in this study. The radar was shut down by the EMS for short periods due to malfunctions and for regular maintenance, and thus $462 \mathrm{~mm}$ of rainfall were recorded by the radar out of the full $512 \mathrm{~mm}$ of rainfall recorded by the rain gauges. We chose 12 radar pixels over the network location and its surroundings for the analysis (Fig. 1) as the area of the gauge network is similar to that of 2-4 joint radar pixels (approximately $4 \mathrm{~km}^{2}$ ).

Rainfall intensity data $\left(R, \mathrm{mmh}^{-1}\right)$ were calculated from the weather radar reflectivity data $\left(Z, \mathrm{~mm}^{6} \mathrm{~m}^{-3}\right)$ by a fixed $Z-R$ power law relationship adjusted using the annual cumulative rainfall amount derived from the dense rain-gauge network. The $Z-R$ relationships were fixed to $Z=126 R^{1.5}$ for the radar pixels; a summarization of the adjustment is given in Table 2. Prior to this adjustment, the radar reflectivity values were increased by $6 \mathrm{~dB}$ to compensate for system losses, as done by Morin and Gabella (2007). A lower threshold of $0.1 \mathrm{mmh}^{-1}$ for noise filtering and an upper threshold of $250 \mathrm{~mm} \mathrm{~h}^{-1}$ to reduce unrealistically strong returns from hail particles were set.

In Fig. 2, scatter plots of synchronous radar (averaged data from the 12 pixels) and rain gauge observations are presented for three timescales: 3 min (the time interval between the radar volume scans), hourly and daily intervals. Ciach and Krajewski (1999) noted that this plot can give an idea of the large amount of variability in the measurements. Here we can see that for the shorter temporal resolution and for the lower rain intensity, the points scatter away from the perfect match line of the radar-to-gauge amounts, possibly due to the problem mentioned above with the unknown tipping-bucket fill time (see previous section).

\section{Spatial correlation of gauge rainfall data}

The spatial rainfall correlation is commonly investigated using Pearson's product-moment correlation (for examples, see Ciach and Krajewski, 2006; Mandapaka et al., 2010; Pedersen et al., 2010; Tokay and Ozturk, 2012; Villarini et al., 2008, and more). Correlograms for different timescales, from $1 \mathrm{~min}$ to daily, were computed using a lag distance of $200 \mathrm{~m}$ (Fig. 3). As expected, the spatial correlation decreased as the separation distance increased and as the timescale decreased. This trend was also shown by Krajewski et al. (2003) for several different experiments conducted worldwide, as well as by Ciach and Krajewski (2006) and Villarini et al. (2008). The correlation was parameterized using a three-parameter exponential function (see fit in Fig. 3), as suggested by Gebremichael and Krajewski (2004), Habib et al. (2001a) and Villarini et al. (2008), for the spatial correlation at separation distance $h$ of the correlogram:

$r(h)=c_{1} \cdot \exp \left[-\left(\frac{h}{c_{2}}\right)^{c_{3}}\right]$,

where $c_{1}$ represents the nugget (zero-distance correlation), $c_{2}$ is the correlation distance and $c_{3}$ is the shape factor.

The time dependence of the parameters given in Eq. (1) are summarized in Fig. 4. The nugget has a value of about 0.92 on the $1 \mathrm{~min}$ scale, increasing to 0.98 for the $5 \mathrm{~min}$ scale and then continuing asymptotically toward 1 on the daily scale. The nugget represents the zero-distance correlation, thus it gives us information about the variability and measurement errors for each side-by-side rain gauge (i.e. each station); when $c_{1}$ is equal to 1 there is a perfect match between the side-by-side gauges. The values obtained in this study were much higher than those reported by Villarini et al. (2008) of $c_{1}=0.5$ on the $1 \mathrm{~min}$ timescale; they are on a scale similar to the values given by Krajewski et al. (2003) of $c_{1}=0.95-0.97$ (different locations worldwide) on timescales of $15 \mathrm{~min}$ or longer. Tokay and Ozturk (2012) reported values of $c_{1}=0.97$ on a $5 \mathrm{~min}$ timescale.

The correlation distance $\left(c_{2}\right)$ increased with the timescale from 3 to $79 \mathrm{~km}$. The correlation distance for $12 \mathrm{~h}(79 \mathrm{~km})$ was much lower than the value of $110 \mathrm{~km}$ estimated by Villarini et al. (2008) or the value of $320 \mathrm{~km}$ estimated by Tokay and Ozturk (2012). The disagreement between the correlation distances can be explained by sample size differences, different estimation methods or statistical artifacts. In addition, as the spatial scale in this study is limited to a distance of a few kilometers because of the network dimensions, we should interpret these very large correlation distances with caution, as was also mentioned by Tokay and Ozturk (2012). 

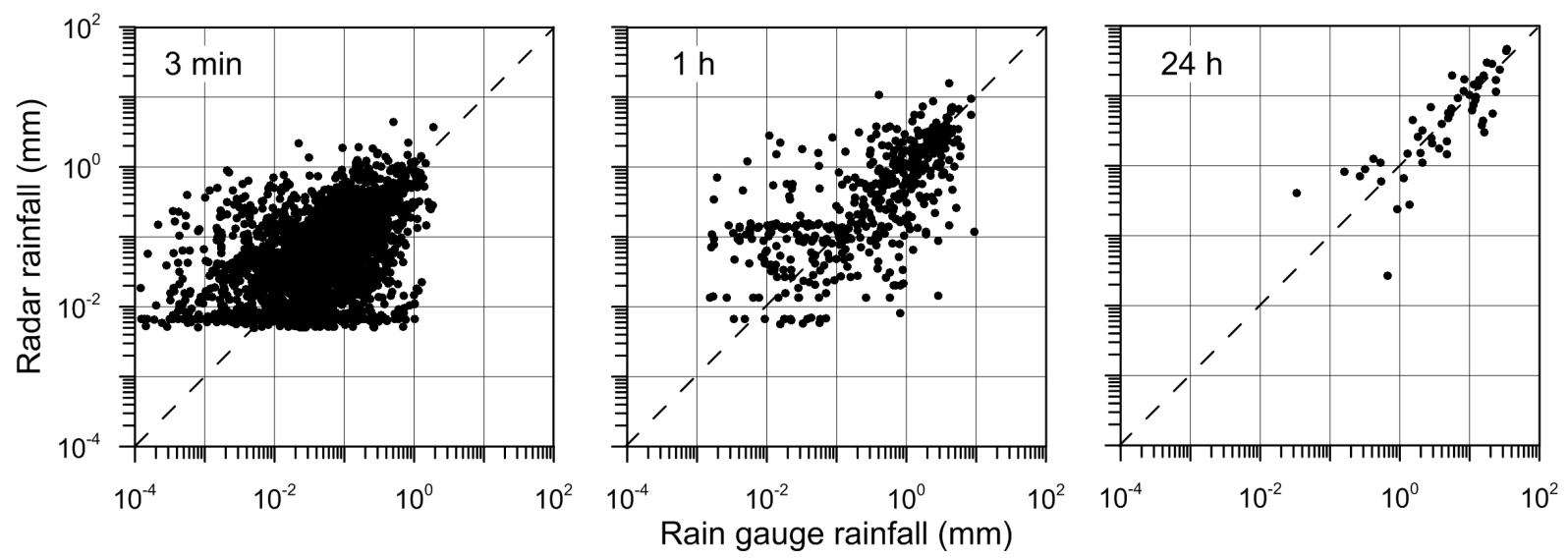

Fig. 2. Scatter plots of synchronous radar and rain gauge observations for $3 \mathrm{~min}$ (radar data are transected along the lower $0.1 \mathrm{mmh}^{-1} \mathrm{rainfall}$ intensity threshold), hourly and daily intervals. The radar rainfall data represent the averaged rainfall derived from the 12 radar pixels. Dashed line represents a perfect fit between gauge and radar rainfall.
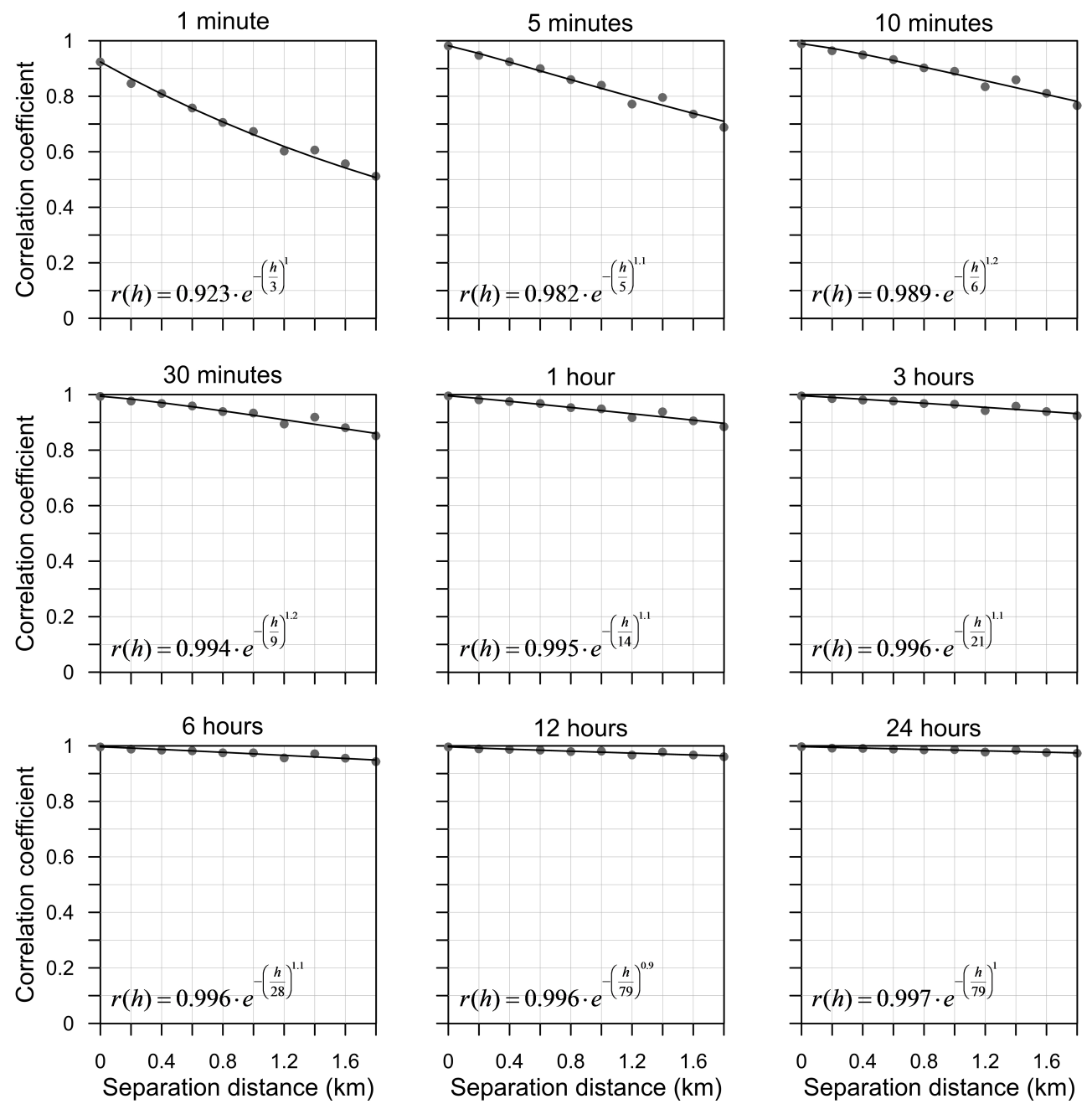

Fig. 3. Correlograms of the rainfall derived from the rain gauges for several timescales (dots) and the fitted three-parameter exponential functions (lines). 

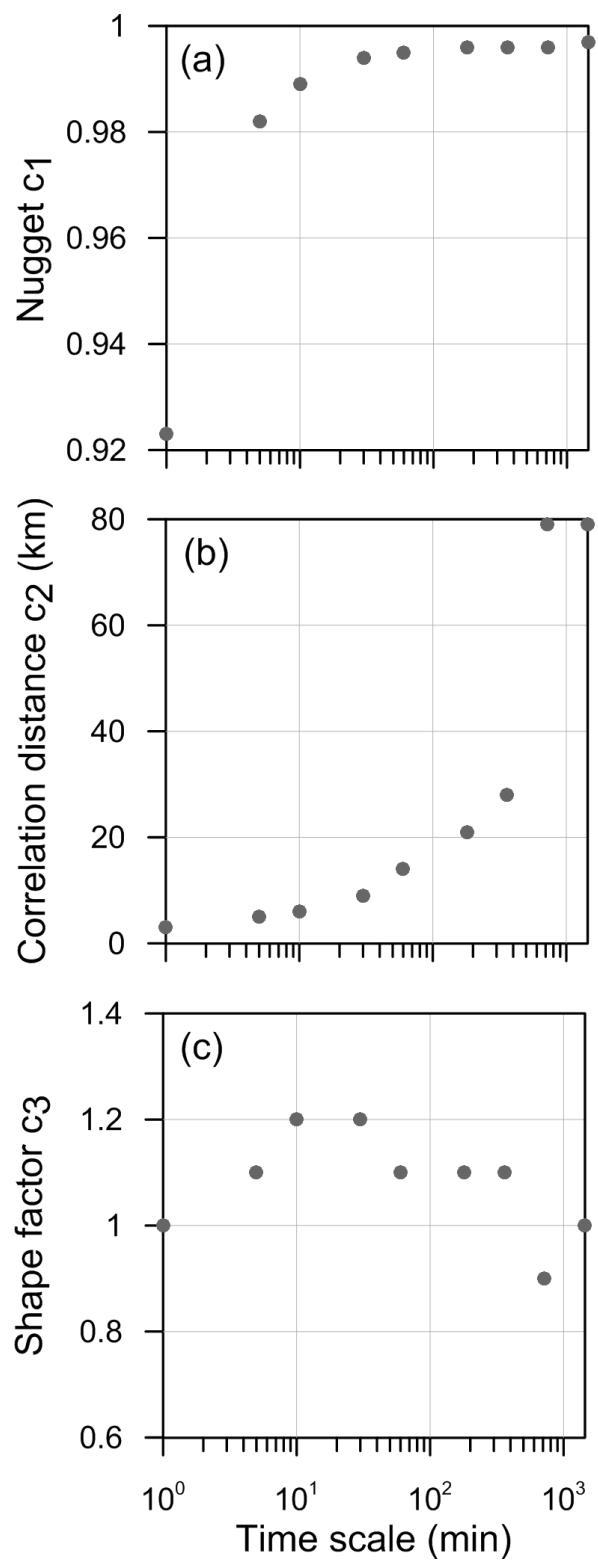

Fig. 4. Time-scale dependence of the nugget (a), correlation distance (b) and shape factor (c) used in the three-parameter exponential function.

In this study, the shape parameter $\left(c_{3}\right)$ was approximately 1 (a pure exponential function), slightly changing from 0.9 to 1.2 with no obvious trend. The shape parameter function estimated in this study was different from those obtained by Ciach and Krajewski (2006), Tokay and Ozturk (2012), and Villarini et al. (2008), where an increase in the shape parameter was detected with an increase in the timescale (between 1.1 and 1.6, 0.37 and 0.92 and 0.4 and 1, respectively). As Villarini et al. (2008) mentioned, differences are expected between experimental studies due to differences in the range of inter-gauge distances, sample size and precipitation type.

\section{Spatial rain gauge uncertainty}

\subsection{Variance reduction factor}

The rainfall variance was estimated by the well-known variance reduction factor (VRF), which has been used by Krajewski et al. (2000) and Villarini et al. (2008) to quantify the uncertainty results from averaging a number of rain gauges. The VRF methodology was introduced by Rodríguez-Iturbe and Mejía (1974) and Bras and Rodríguez-Iturbe (1976). Morrissey et al. (1995) proposed a numerical method which considered the number of rain gauges, their spatial distribution, and the correlation between them. In this paper, we provide only a brief discussion of the VRF methodology; for further details, the reader is referred to the above-mentioned papers.

Let $R_{\mathrm{S}}$ be the point rainfall of a single rain station (two side-by-side gauges per station), $\bar{R}_{\mathrm{S}}$ be the averaged-areal rainfall derived from the rain stations, and let $R_{\mathrm{t}}$ be the true areal rainfall. The mean square error of the true rainfall to the averaged-areal rainfall can be expressed as:

$E\left[\left(R_{\mathrm{t}}-\bar{R}_{\mathrm{S}}\right)^{2}\right]=\sigma_{R_{\mathrm{S}}}^{2} \cdot \mathrm{VRF}$,

where $\sigma_{R_{\mathrm{s}}}^{2}$ is the variance of the point rainfall and the VRF is computed by

$$
\begin{aligned}
& \operatorname{VRF}=\frac{1}{n^{2}} \cdot \sum_{i=1}^{N} \sum_{j=1}^{N} \rho\left(d_{i, j}\right) \cdot \delta(i) \cdot \delta(j)-\frac{2}{N \cdot n} \\
& \cdot \sum_{i=1}^{N} \sum_{j=1}^{N} \rho\left(d_{i, j}\right) \cdot \delta(i)+\frac{1}{N}+\frac{2}{N^{2}} \cdot \sum_{i=1}^{N-1} \sum_{j=i+1}^{N} \rho\left(d_{i, j}\right),
\end{aligned}
$$

where $n$ is the number of rainfall measuring stations, $N$ is the number of boxes dividing the domain, $\rho\left(d_{i, j}\right)$ is the correlation coefficient derived from Eq. (1) for the distance between boxes $i$ and $j$, and $\delta$ is a Boolean value with a value of 1 when box $i$ contains a measuring station (each box can contain only one measuring station) and a value of 0 otherwise.

The domain area was defined with dimensions of $2.1 \times 2.1 \mathrm{~km}$ in order to capture all of the rain stations $(n=$ 14) participating in this study (Fig. 1; see the $4 \mathrm{~km}^{2}$ box for comparison). The grid was composed of 441 boxes $(N)$, each with a size of $100 \times 100 \mathrm{~m}$. The results are plotted in Fig. 5a. The VRF was $1.6 \%$ for a timescale of $1 \mathrm{~min}$ and it decreased with increasing time accumulated to $0.07 \%$ for the daily timescale. These results are similar to those presented by Villarini et al. (2008) for a $4 \mathrm{~km}^{2}$ domain, where the VRF decreased from approximately $2.7 \%$ for a timescale of $1 \mathrm{~min}$ to near zero for the daily timescale. The VRF is very close to zero, meaning that the left side of Eq. (2) is also close to zero; thus for any given timescale, the true rainfall will be well represented by the averaged-areal rainfall.

The minimum number of rain stations required for a good representation of this small $4 \mathrm{~km}^{2}$ domain was determined. 

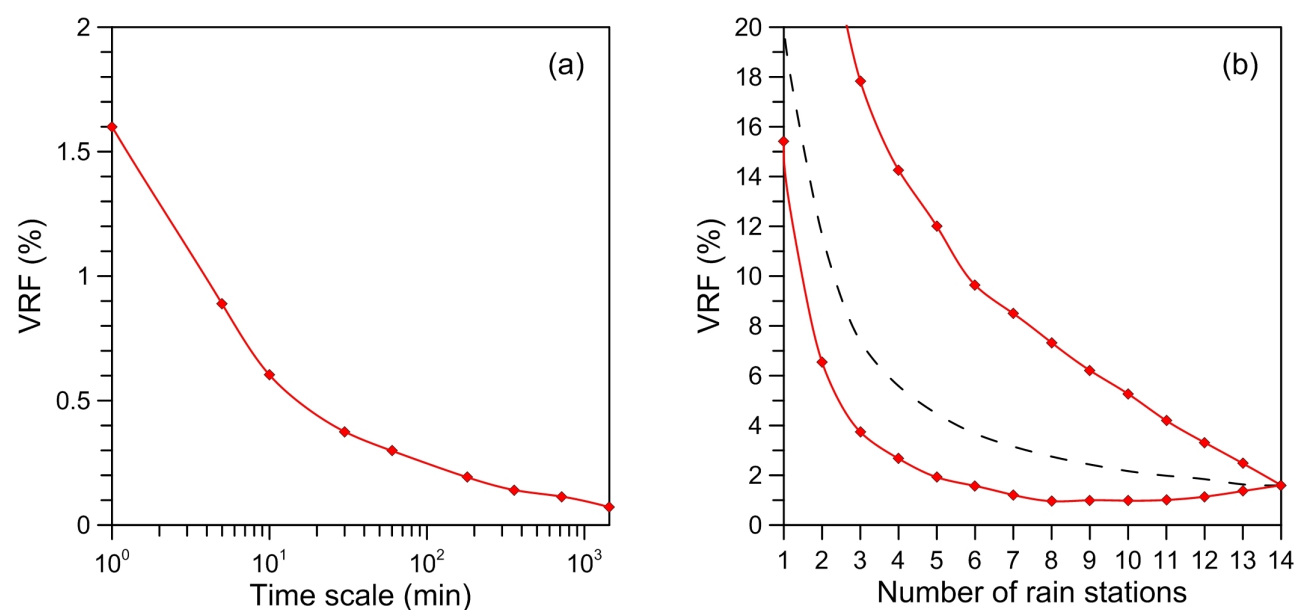

Fig. 5. Variance reduction factor (VRF) as a function of (a) timescale and (b) number of rain stations in the study area for the 1 min timescale (maximum, minimum and median).

The VRF was computed from one station to 14 stations where all possible combinations were calculated. As the results for the different timescales are similar, only the results for the 1 min timescale are plotted in Fig. $5 b$ and discussed here. Examining the minimum VRF values suggested that setting up three rain stations in a specific configuration within a radar pixel domain is sufficient to represent the rainfall within the radar pixel, assuming that the VRF threshold of $5 \%$ is satisfied. VRF values lower than $2 \%$ will require at least five rain stations in the domain. The lowest VRF was found for the setting of 10 rain stations $(0.99 \%)$ in the domain. The VRF increases with the addition of more than 10 rain stations as the distances between the rain stations decrease, resulting in an increase of the first term in Eq. (3).

\subsection{Convective rainfall}

The contribution of convective rainfall to the total precipitation over the study area cannot be overlooked. To check whether there are differences in the spatial correlation of the convective versus nonconvective rainfall, we divided the rainfall series at the $5 \mathrm{~min}$ timescale as follows: if at least one of the rain gauges recorded rain intensity exceeding $10 \mathrm{mmh}^{-1}$, this $5 \mathrm{~min}$ interval was marked as convective (it was summed up to $242 \mathrm{~mm}$ - about $47 \%$ of the total measured rainfall); if all rain gauges recorded rain intensity lower than $10 \mathrm{~mm} \mathrm{~h}^{-1}$, it was marked as nonconvective. This threshold was used by Peleg and Morin (2012) to distinguish the convective rain cells from the total precipitation in the same area.

The spatial correlation for the convective and nonconvective rainfall for the $5 \mathrm{~min}$ timescale was calculated using the methodology explained in Sect. 3, and is presented in Fig. 6a. The nugget of the convective precipitation is 0.97 , while the nugget of the nonconvective rainfall is 0.95 . The convective spatial correlation decreases rapidly to 0.4 at a separation dis- tance of $1.8 \mathrm{~km}$, while the nonconvective spatial correlation decreases more moderately to 0.7 at the same distance. The nonconvective spatial correlation decays in a manner similar to the 5 min correlation decay of the combined convective and nonconvective rainfall presented in Fig. 3. The fast decay of the convective rainfall spatial correlation implies that the areal rainfall variance is high. The standard deviation of the convective rainfall, normalized by its mean, was plotted against the fraction of rain gauges exceeding the threshold of $10 \mathrm{mmh}^{-1}$ (Fig. 6b). The normalized standard deviation (NSTD) of the convective rainfall is about 0.4. The maximum NSTD is higher for fewer rain gauges that detect rain intensity exceeding the threshold.

\section{Radar estimation error}

\subsection{Error separation method}

Ciach and Krajewski (1999) proposed the error separation method (ESM) which separates the radar-rain gauge error in two: the radar-true area-averaged rainfall error and the rain gauge sampling error. Below is a short description of the method; for further information the reader is referred to Ciach and Krajewski (1999) and to an additional example by Krajewski et al. (2000).

Let $R_{\mathrm{r}}$ be the rainfall estimated from the radar, $R_{\mathrm{g}}$ the rainfall as measured by the rain gauge and $R_{\mathrm{t}}$ the true areaaveraged rainfall. The normalized root mean square error of the radar-estimated rainfall versus the rain gauges is found by

$\operatorname{NRMSE}\left(R_{\mathrm{r}}-R_{\mathrm{g}}\right)=\frac{\sqrt{\frac{\sum_{i=1}^{N}\left(R_{\mathrm{r}}(i)-R_{\mathrm{g}}(i)\right)^{2}}{N}}}{\bar{R}_{\mathrm{g}}}$, 

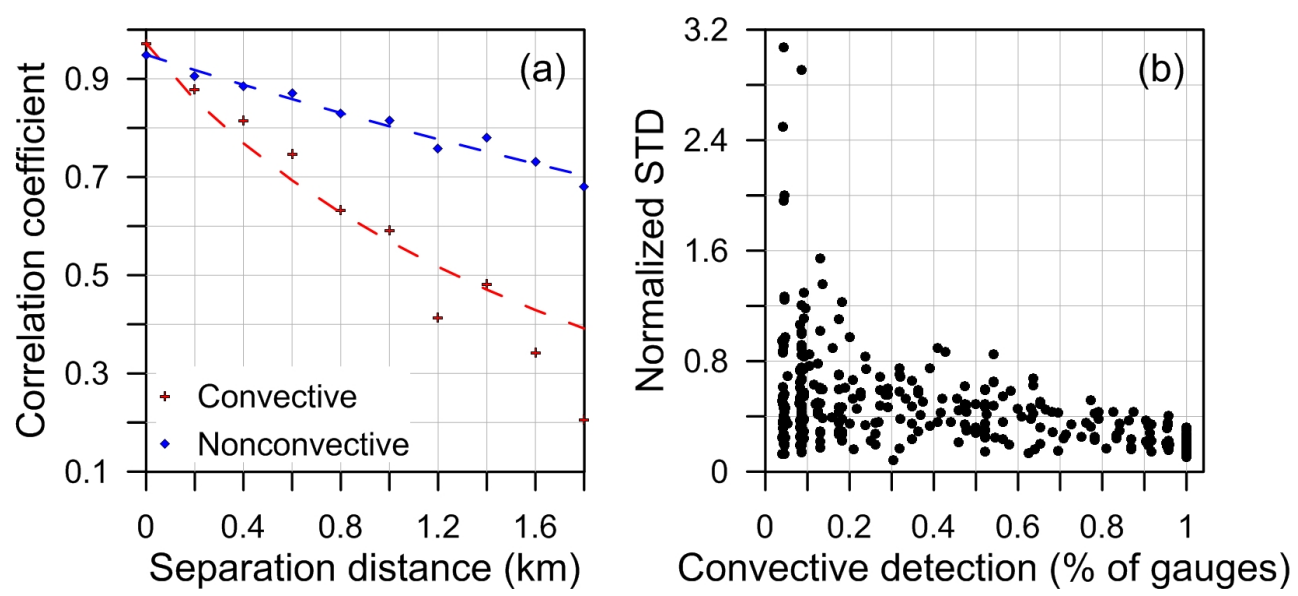

Fig. 6. (a) Correlogram presenting the convective (red plus symbol) and nonconvective (blue dots) spatial rainfall coefficient and its fit (dashed lines) using the three-parameter exponential functions. (b) Convective rain intensity normalized standard deviation. The analysis was performed for the $5 \mathrm{~min}$ rain intensity data.

where $N$ is the sample size and $\bar{R}_{\mathrm{g}}$ is the averaged rainfall measured by the gauges. The normalized rain gauge sampling error can be determined (based on Eq. (18) in Ciach and Krajewski, 1999) by

$\operatorname{NRMSE}\left(R_{\mathrm{g}}-R_{\mathrm{t}}\right)=\frac{\sqrt{\operatorname{var}\left(R_{\mathrm{g}}\right) \cdot\left(1-c_{1}\right)}}{\bar{R}_{\mathrm{g}}}$,

where $c_{1}$ is the nugget. The radar-true area-averaged rainfall error can be then solved by

$\operatorname{var}\left\{R_{\mathrm{r}}-R_{\mathrm{t}}\right\}=\operatorname{var}\left\{R_{\mathrm{r}}-R_{\mathrm{g}}\right\}-\operatorname{var}\left\{R_{\mathrm{g}}-R_{\mathrm{t}}\right\}$,

where $\operatorname{var}\left\{R_{\mathrm{r}}-R_{\mathrm{g}}\right\}$ and $\operatorname{var}\left\{R_{\mathrm{g}}-R_{\mathrm{r}}\right\}$ are derived from Eqs. (4) and (5), respectively. For the above computation, we assume that there is no bias between the rainfall measured by the rain gauges and the rainfall measured by the weather radar, as each radar pixel is adjusted separately for the data derived from the gauges.

The results of the ESM for the different timescales are presented in Fig. 7 for the relative magnitude of each of the method components. The normalized radar-true rainfall error is presented for the maximum and minimum values obtained from the 12 radar pixels tested (i.e. maximum and minimum values represent one pixel each and the other 10 pixel values are found in the range between). The radar raingauge error declines from a maximum $615 \%$ error (minimum of $351 \%$ ) for a timescale of 3 min to a maximum $78 \%$ error (minimum $68 \%$ ) for the daily timescale. The error derived from the rain gauge sampling error is reduced from $71 \%$ for a timescale of $3 \min$ to $5 \%$ for a daily timescale. The gauge sampling error contributes only a relatively small part of the overall error: it changes from $20 \%$ (minimum contribution of $11.5 \%$ ) for the 3 min timescale to $8 \%$ (minimum of $7 \%$ ) for the daily timescale.

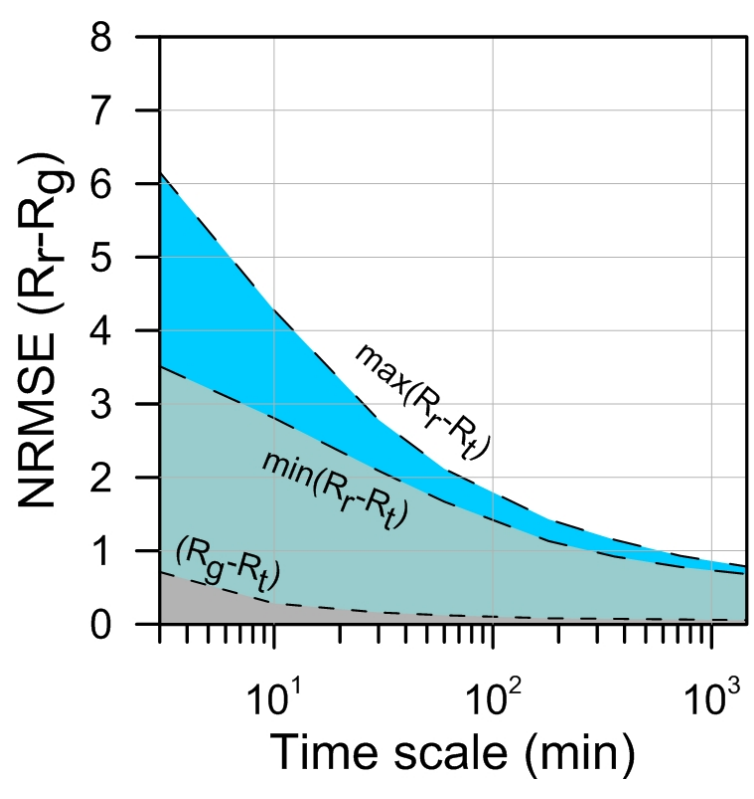

Fig. 7. Errors of radar $\left(R_{\mathrm{r}}\right)$ vs. gauge $\left(R_{\mathrm{g}}\right)$ rainfall for different timescales. The normalized root mean square errors of radar rainfall $\left(R_{\mathrm{r}}\right)$ vs. true rainfall $\left(R_{\mathrm{t}}\right)$ were analyzed independently for 12 radar pixels. The maximum and minimum are presented by the blue sections. Gray section represents the spatial sampling error derived from the rain gauge $\left(R_{\mathrm{g}}\right)$ vs. true areal rainfall $\left(R_{\mathrm{t}}\right)$.

\subsection{Radar rainfall evaluation}

The radar rainfall was evaluated using the critical success index (CSI), false alarm ratio (FAR) and probability of detection (POD) parameters, all well-known parameters which have been used in numerous studies (for example: Dixon and Wiener, 1993; Germann et al., 2006; Kyznarova and Novak, 
2009). These quality parameters are defined as

$$
\begin{aligned}
\mathrm{CSI} & =\frac{H}{H+F+M} \\
\mathrm{FAR} & =\frac{F}{H+F} \\
\mathrm{POD} & =\frac{H}{H+M},
\end{aligned}
$$

where $H$ is the number of hits - both radar and gauged areal average rainfall indicate rain; $M$ means number of misses - rainfall was only recorded by rain gauges; $F$ means false alarms - rainfall was only recorded by radar. A zero threshold was used to mark the occurrence of rain. This means that the lower threshold for the radar was defined as $0.1 \mathrm{mmh}^{-1}$ (see Sect. 2.2), while the averaged gauged rainfall was indicative for rain as at least one rain gauge recorded rain.

The evaluation was conducted for different timescales for each of the radar pixels and for the radar pixel average, and the results are presented in Fig. 8. All quality parameters improved as the timescale increased, in a manner similar to the ESM results discussed in the previous section. The CSI for the averaged radar pixel changed from 0.41 for the $3 \mathrm{~min}$ timescale to 1 for the daily timescale and its POD increased from 0.6 to 1 for the same timescales. The FAR decreased from 0.42 for the $3 \mathrm{~min}$ timescale to zero for the $3 \mathrm{~h}$ timescale and on. These results are affected by the threshold set to define a rain occurrence, where higher threshold changes the CSI, POD and FAR results.

The ratio of averaged radar rainfall to true areal rainfall was calculated for $3 \mathrm{~min}, 30 \mathrm{~min}$ and daily timescales. Here, we assumed that the true rainfall is well represented by the areal-averaged gauge-derived rainfall. The cumulative distribution (weighted by contribution to total rain amount) of the radar-to-true rainfall ratio (in $\mathrm{dB}$ ) is presented in Fig. 9, following Germann et al. (2006). For the 3 min timescale, the radar underestimated about $70 \%$ of the rainfall, with the radar-to-true rainfall ratio reaching up to $-22 \mathrm{~dB}$. For the daily timescale, the radar estimations improved, with the inflection point between the under- and overestimation found around the $50 \%$ rainfall contribution and the radarto-true rainfall ratio being as low as $-14 \mathrm{~dB}$. The improvement of the radar estimation for the true rainfall with increasing timescale was also expressed by the scatter parameter, defined as half the distance between the 16th and 84th percentiles of the error distribution (Germann et al., 2006). The scatter decreased from $5.27 \mathrm{~dB}$ for the $3 \mathrm{~min}$ timescale to $3.21 \mathrm{~dB}$ for the daily timescale.

\section{Conclusions}

Subpixel rain distribution was investigated using a highdensity network of rain gauges within a $4 \mathrm{~km}^{2}$ area as a part of continuous efforts to better understand the uncertainties and errors of rainfall estimation at this scale. This is
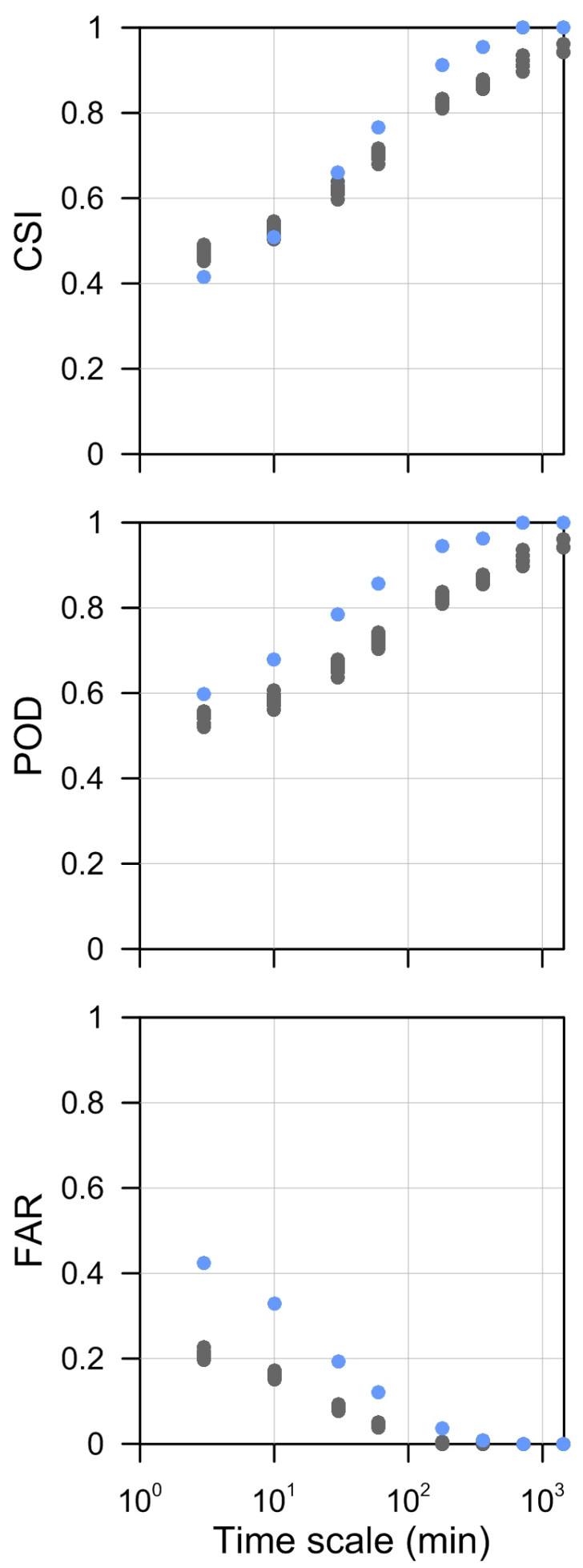

Fig. 8. Critical success index (CSI), probability of detection (POD) and false alarm ratio (FAR) for the different timescales. Gray dots represent the radar pixels and blue dots represent the averaged radar pixels. 

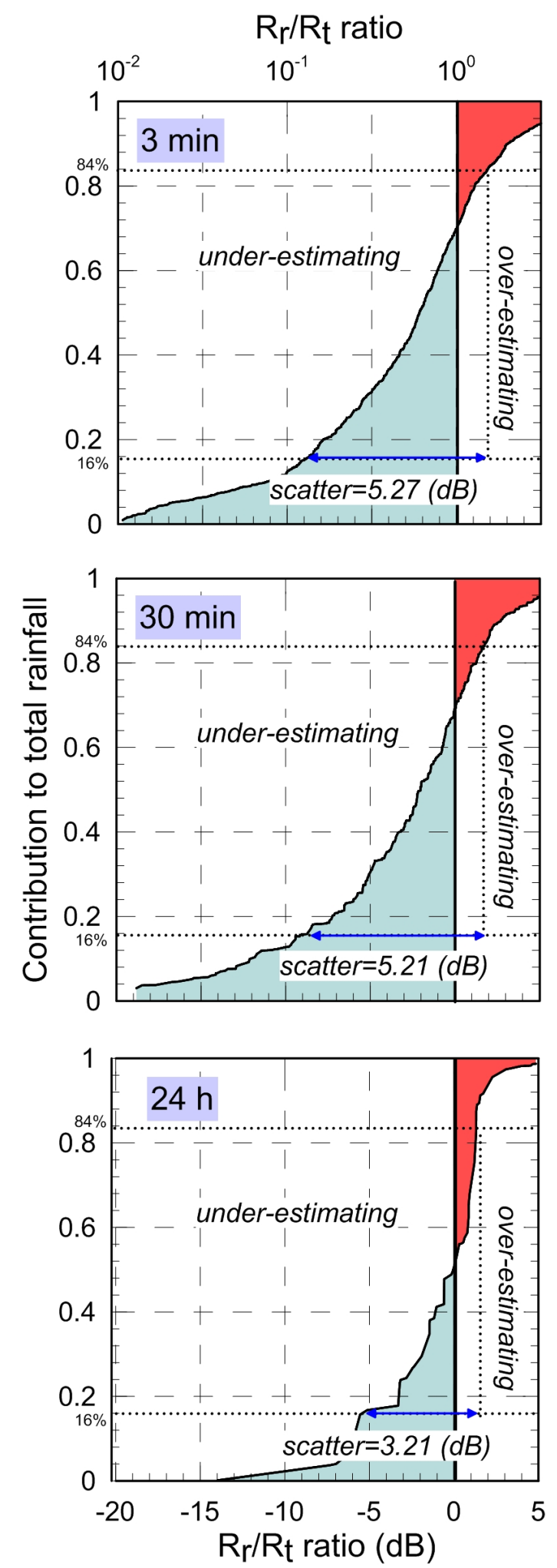

Fig. 9. Cumulative distribution (weighted by contribution to total rain amount) of the radar-to-true rainfall ratio $\left(R_{\mathrm{r}} / R_{\mathrm{t}}\right.$, in $\left.\mathrm{dB}\right)$ (see Germann et al., 2006) for different timescales. of particular importance when using remote sensing rainfall data (from ground weather radar or from satellite) for hydrological applications. In this study, we used the network of 27 tipping-bucket rain gauges located in northern Israel to evaluate the Shacham weather radar's performance and to learn about small-scale rainfall variability. From the first year of observation three lessons were learned:

- First, we examined the spatial correlation of gauge rainfall data as has been done before for different locations worldwide. We found that the nugget (zerodistance correlation) between rain gauges is high $(0.92$ for the $1 \mathrm{~min}$ timescale) and it increases with increasing timescale. Moreover, spatial rainfall correlations for all separation distances generally increase with timescale. The more important finding was that there is a difference in spatial correlations between convective and nonconvective rainfall, where the convective rainfall correlation decreases much faster with distance than the nonconvective. Convective rainfall correlations have long been a subject for study (for example, see papers by Sharon, 1974; Osborn et al., 1979) but, to the best of our knowledge, this is the first time that this examination has been performed at the radar pixel scale. The fast decay of convective rainfall correlation within a radar pixel may imply that the radar errors for high rainfall intensity are even larger than thought. Further investigation is needed to understand the spatial and temporal differences between the different types of rainfall and its effects on radar data.

- The second lesson learned was derived from the variance reduction factor. It was found that the VRF decreases as the timescale increases, from $1.6 \%$ for the 1 min scale to $0.07 \%$ for the daily timescale. This led to the conclusion that for any given timescale the average rainfall derived from the gauge network well represents the pixel-scale. This raises the question of how many rain stations are needed within a radar pixel for a good representation of rainfall at this scale. We found this question important for regular maintenance of the network (for example, when it is necessary to remove some rain gauges for calibration) and for future planning of other networks in similar climatological conditions (as the VRF is dependent on rainfall correlation). If the $5 \%$ threshold is selected as a criterion for adequate representation of subpixel rainfall distribution then, according to our analysis, three rain stations in a specific configuration are sufficient to represent the rainfall within the radar pixel. At least five rain stations are required to represent the radar rainfall with a VRF threshold of $2 \%$. The decision as to which VRF threshold to use, however, remains subjective. This finding can be used in validation procedures of remote sensing rainfall products with a similar pixel size. In the majority of cases, only one rain gauge is located within each validated pixel, 
while our results indicate that to remove uncertainties related to subpixel rainfall distribution three rain gauges per pixel are better, at least for a similar climate. Obviously, this will increase the cost of such a network; however, it will also assure meaningful validation results.

- Lastly, we debate the question of which radar temporal resolution should be used for hydrological applications. A possible answer to this question is to fit the required temporal resolution to the basin hydrological response that depends on catchment size, land use and other properties (Morin et al., 2001). Berne et al. (2004) suggested a temporal scale of 3-5 min for urban catchments of the order of $1-10 \mathrm{~km}^{2}$, while Atencia et al. (2011) suggested a temporal scale of 12-15 min for basins of the order of $100-1000 \mathrm{~km}^{2}$. Another aspect to consider is radar errors for the pixel scale and its change with time (Fig. 7). It was found that the radar-rain gauge error decreases from $477 \%$ for the $3 \mathrm{~min}$ timescale to $345 \%$ for the $10 \mathrm{~min}$ scale and down to $72 \%$ for the daily timescale (all are areal mean values). This error is mainly the result of radar estimation errors, as the gauge sampling error contributes only $8-20 \%$ to the total error, depending on the timescale. The improvement in radar rainfall estimations with increasing timescale is reflected by the increase of the CSI and POD parameters with timescale and the simultaneous decrease of the FAR parameter. In addition, the radar-to-true rainfall ratio, expressed by the scatter parameter, decreases with increasing timescale from $5.27 \mathrm{~dB}$ for the 3 min scale to $3.21 \mathrm{~dB}$ for the daily scale. Based on these results, we recommend utilizing the radar rainfall data at scales of at least $10 \mathrm{~min}$, thus benefiting from the large reduction in error from $3 \mathrm{~min}$ timescale to the $10 \mathrm{~min}$ scale.

We intend to continue collecting rainfall measurements with this network of rain gauges in the years to come. In December 2012, a disdrometer was installed at this site to measure rain drop size distribution (e.g., Jaffrain et al., 2011). We are looking for new and better ways to continue developing this network for future use with other weather radar or satellite observations.

Acknowledgements. The authors thank Kibbutz Galed for their valuable assistance and cooperation and also to Camille Vainstein for her editorial work. The research was supported by the Israeli Ministry of Environmental Protection and THE ISRAEL SCIENCE FOUNDATION - The Recanati and IDB Group Foundation (grant No. 332/11). We thank the two reviewers (Hidde Leijnse and the second anonymous reviewer) and the editor for their significant contribution to the quality of the paper.

Edited by: A. Langousis

\section{References}

Amitai, E., Unkrich, C. L., Goodrich, D. C., Habib, E., and Thill, B.: Assessing satellite-based rainfall estimates in semiarid watersheds using the USDA-ARS walnut gulch gauge network and TRMM PR, J. Hydrometeorol., 13, 1579-1588, doi:10.1175/jhm-d-12-016.1, 2012.

Arnaud, P., Lavabre, J., Fouchier, C., Diss, S., and Javelle, P.: Sensitivity of hydrological models to uncertainty in rainfall input, Hydrol. Sci. J.-J. Sci. Hydrol., 56, 397-410, doi:10.1080/02626667.2011.563742, 2011.

Atencia, A., Mediero, L., Llasat, M. C., and Garrote, L.: Effect of radar rainfall time resolution on the predictive capability of a distributed hydrologic model, Hydrol. Earth Syst. Sci., 15, 38093827, doi:10.5194/hess-15-3809-2011, 2011.

Bahat, Y., Grodek, T., Lekach, J., and Morin, E.: Rainfall-runoff modeling in a small hyper-arid catchment, J. Hydrol., 373, $204-$ 217, doi:10.1016/j.jhydrol.2009.04.026, 2009.

Berne, A. and Krajewski, W. F.: Radar for hydrology: Unfulfilled promise or unrecognized potential?, Adv. Water Resour., 51, 357-366, doi:10.1016/j.advwatres.2012.05.005, 2013.

Berne, A., Delrieu, G., Creutin, J. D., and Obled, C.: Temporal and spatial resolution of rainfall measurements required for urban hydrology, J. Hydrol., 299, 166-179, doi:10.1016/j.jhydrol.2004.08.002, 2004.

Bras, R. L. and Rodríguez-Iturbe, I.: Evaluation of mean square error involved in approximating the areal average of a rainfall event by a discrete summation, Water Resour. Res., 12, 181-184, doi:10.1029/WR012i002p00181, 1976.

Ciach, G. J.: Local random errors in tipping-bucket rain gauge measurements, J. Atmos. Ocean. Technol., 20, 752-759, doi:10.1175/1520-0426(2003)20<752:1reitb > 2.0.co;2, 2003.

Ciach, G. J. and Krajewski, W. F.: On the estimation of radar rainfall error variance, Adv. Water Resour., 22, 585-595, doi:10.1016/s0309-1708(98)00043-8, 1999.

Ciach, G. J. and Krajewski, W. F.: Analysis and modeling of spatial correlation structure in small-scale rainfall in Central Oklahoma, Adv. Water Resour., 29, 1450-1463, doi:10.1016/j.advwatres.2005.11.003, 2006.

Dixon, M. and Wiener, G.: TITAN - thunderstorm identification, tracking, analysis, and nowcasting - a radar-based methodology, J. Atmos. Ocean. Technol., 10, 785-797, doi:10.1175/15200426(1993)010<0785:ttitaa>2.0.co;2, 1993.

Faures, J. M., Goodrich, D. C., Woolhiser, D. A., and Sorooshian, S.: Impact of small-scale spatial rainfall variability on runoff modeling, J. Hydrol., 173, 309-326, doi:10.1016/00221694(95)02704-s, 1995.

Fiener, P. and Auerswald, K.: Spatial variability of rainfall on a sub-kilometre scale, Earth Surf. Proc. Land., 34, 848-859, doi:10.1002/esp.1779, 2009.

Gebremichael, M. and Krajewski, W. F.: Assessment of the statistical characterization of small-scale rainfall variability from radar: Analysis of TRMM ground validation datasets, J. Appl. Meteorol., 43, 1180-1199, doi:10.1175/15200450(2004)043<1180:aotsco>2.0.co;2, 2004.

Germann, U., Galli, G., Boscacci, M., and Bolliger, M.: Radar precipitation measurement in a mountainous region, Q. J. Roy. Meteor. Soc., 132, 1669-1692, doi:10.1256/qj.05.190, 2006.

Habib, E., Krajewski, W. F., and Ciach, G. J.: Estimation of rainfall interstation correlation, J. Hydrometeorol., 2, 621-629, 
doi:10.1175/1525-7541(2001)002<0621:eoric > 2.0.co;2, 2001a.

Habib, E., Krajewski, W. F., and Kruger, A.: Sampling errors of tipping-bucket rain gauge measurements, J. Hydrol. Eng., 6, 159-166, doi:10.1061/(asce)1084-0699(2001)6:2(159), 2001b.

Jaffrain, J., Studzinski, A., and Berne, A.: A network of disdrometers to quantify the small-scale variability of the raindrop size distribution, Water Resour. Res., 47, W00h06, doi:10.1029/2010wr009872, 2011.

Jensen, N. E. and Pedersen, L.: Spatial variability of rainfall: Variations within a single radar pixel, Atmos. Res., 77, 269-277, doi:10.1016/j.atmosres.2004.10.029, 2005.

Karklinsky, M. and Morin, E.: Spatial characteristics of radarderived convective rain cells over southern Israel, Meteorol. Z., 15, 513-520, doi:10.1127/0941-2948/2006/0153, 2006.

Krajewski, W. F. and Smith, J. A.: Radar hydrology: rainfall estimation, Adv. Water Resour., 25, 1387-1394, doi:10.1016/s03091708(02)00062-3, 2002.

Krajewski, W. F., Kruger, A., and Nespor, V.: Experimental and numerical studies of small-scale rainfall measurements and variability, Water Sci. Technol., 37, 131-138, doi:10.1016/s02731223(98)00325-4, 1998.

Krajewski, W. F., Ciach, G. J., McCollum, J. R., and Bacotiu, C.: Initial validation of the global precipitation climatology project monthly rainfall over the United States, J. Appl. Meteorol., 39, 1071-1086, doi:10.1175/15200450(2000)039<1071:ivotgp > 2.0.co;2, 2000.

Krajewski, W. F., Ciach, G. J., and Habib, E.: An analysis of smallscale rainfall variability in different climatic regimes, Hydrol. Sci. J., 48, 151-162, doi:10.1623/hysj.48.2.151.44694, 2003.

Krajewski, W. F., Villarini, G., and Smith, J. A.: Radar-rainfall uncertainties - where are we after thirty years of effort?, B. Am. Meteorol. Soc., 91, 87-94, doi:10.1175/2009bams2747.1, 2010.

Kyznarova, H. and Novak, P.: CELLTRACK - Convective cell tracking algorithm and its use for deriving life cycle characteristics, Atmos. Res., 93, 317-327, doi:10.1016/j.atmosres.2008.09.019, 2009.

Mandapaka, P. V., Villarini, G., Seo, B. C., and Krajewski, W. F.: Effect of radar-rainfall uncertainties on the spatial characterization of rainfall events, J. Geophys. Res.-Atmos., 115, D17110, doi:10.1029/2009jd013366, 2010.

Moore, R. J., Jones, D. A., Cox, D. R., and Isham, V. S.: Design of the HYREX raingauge network, Hydrol. Earth Syst. Sci., 4, 521-530, doi:10.5194/hess-4-521-2000, 2000.

Morin, E. and Gabella, M.: Radar-based quantitative precipitation estimation over Mediterranean and dry climate regimes, J. Geophys. Res.-Atmos., 112, D20108, doi:10.1029/2006jd008206, 2007.

Morin, E., Enzel, Y., Shamir, U., and Garti, R.: The characteristic time scale for basin hydrological response using radar data, J. Hydrol., 252, 85-99, doi:10.1016/s0022-1694(01)004516, 2001.

Morin, E., Goodrich, D. C., Maddox, R. A., Gao, X. G., Gupta, H. V., and Sorooshian, S.: Spatial patterns in thunderstorm rainfall events and their coupling with watershed hydrological response, Adv. Water Resour., 29, 843-860, doi:10.1016/j.advwatres.2005.07.014, 2006.

Morin, E., Jacoby, Y., Navon, S., and Bet-Halachmi, E.: Towards flash-flood prediction in the dry Dead Sea region utilizing radar rainfall information, Adv. Water Resour., 32, 1066-1076, doi:10.1016/j.advwatres.2008.11.011, 2009.

Morrissey, M. L., Maliekal, J. A., Greene, J. S., and Wang, J. M.: THe uncertainty of simple spatial averages using rain-gauge networks, Water Resour. Res., 31, 2011-2017, doi:10.1029/95wr01232, 1995.

Nikolopoulos, E. I., Anagnostou, E. N., Hossain, F., Gebremichael, M., and Borga, M.: Understanding the scale relationships of uncertainty propagation of satellite rainfall through a distributed hydrologic model, J. Hydrometeorol., 11, 520-532, doi:10.1175/2009jhm1169.1, 2010.

Osborn, H. B., Renard, K. G., and Simanton, J. R.: Dense networks to measure convective rainfall in the southwestern United States, Water Resour. Res., 15, 1701-1711, doi:10.1029/WR015i006p01701, 1979.

Pedersen, L., Jensen, N. E., Christensen, L. E., and Madsen, H.: Quantification of the spatial variability of rainfall based on a dense network of rain gauges, Atmos. Res., 95, 441-454, doi:10.1016/j.atmosres.2009.11.007, 2010.

Peleg, N. and Morin, E.: Convective rain cells: Radar-derived spatiotemporal characteristics and synoptic patterns over the eastern Mediterranean, J. Geophys. Res., 117, D15116, doi:10.1029/2011jd017353, 2012.

Rodríguez-Iturbe, I. and Mejía, J. M.: The design of rainfall networks in time and space, Water Resour. Res., 10, 713-728, doi:10.1029/WR010i004p00713, 1974.

Rozalis, S., Morin, E., Yair, Y., and Price, C.: Flash flood prediction using an uncalibrated hydrological model and radar rainfall data in a Mediterranean watershed under changing hydrological conditions, J. Hydrol., 394, 245-255, doi:10.1016/j.jhydrol.2010.03.021, 2010.

Seo, B. C. and Krajewski, W. F.: Investigation of the scaledependent variability of radar-rainfall and rain gauge error covariance, Adv. Water Resour., 34, 152-163, doi:10.1016/j.advwatres.2010.10.006, 2011.

Sharon, D.: The spatial pattern of convective rainfall in Sukumaland, Tanzani - A statistical analysis, Arch. Met. Geoph. Biokl. B., 22, 201-218, doi:10.1007/bf02243468, 1974.

Singh, V. P.: Effect of spatial and temporal variability in rainfall and watershed characteristics on stream flow hydrograph, Hydrol. Process., 11, 1649-1669, doi:10.1002/(sici)10991085(19971015)11:12<1649::aid-hyp495>3.0.co;2-1, 1997.

Tapiador, F. J., Checa, R., and de Castro, M.: An experiment to measure the spatial variability of rain drop size distribution using sixteen laser disdrometers, Geophys. Res. Lett., 37, L16803, doi:10.1029/2010g1044120, 2010.

Tokay, A. and Ozturk, K.: An Experimental Study of the SmallScale Variability of Rainfall, J. Hydrometeorol., 13, 351-365, doi:10.1175/jhm-d-11-014.1, 2012.

Tokay, A. and Bashor, P. G.: An Experimental Study of SmallScale Variability of Raindrop Size Distribution, J. Appl. Meteorol. Clim., 49, 2348-2365, doi:10.1175/2010jamc2269.1, 2010.

Villarini, G., Mandapaka, P. V., Krajewski, W. F., and Moore, R. J.: Rainfall and sampling uncertainties: A rain gauge perspective, J. Geophys. Res.-Atmos., 113, D11102, doi:10.1029/2007jd009214, 2008.

Wang, J. X., Fisher, B. L., and Wolff, D. B.: Estimating rain rates from tipping-bucket rain gauge measurements, J. Atmos. Ocean. Tech., 25, 43-56, doi:10.1175/2007jtecha895.1, 2008. 
Wood, S. J., Jones, D. A., and Moore, R. J.: Accuracy of rainfall measurement for scales of hydrological interest, Hydrol. Earth Syst. Sci., 4, 531-543, doi:10.5194/hess-4-531-2000, 2000.

Yakir, H. and Morin, E.: Hydrologic response of a semi-arid watershed to spatial and temporal characteristics of convective rain cells, Hydrol. Earth Syst. Sci., 15, 393-404, doi:10.5194/hess15-393-2011, 2011.
Zoccatelli, D., Borga, M., Viglione, A., Chirico, G. B., and Blöschl, G.: Spatial moments of catchment rainfall: rainfall spatial organisation, basin morphology, and flood response, Hydrol. Earth Syst. Sci., 15, 3767-3783, doi:10.5194/hess-15-37672011, 2011. 